\title{
Location of Biorefineries Based on Olive-Derived Biomass in Andalusia, Spain
}

\author{
Diego Cardoza ${ }^{1}$, Inmaculada Romero ${ }^{1,2, *(\mathbb{D})}$, Teresa Martínez ${ }^{3}$, Encarnación Ruiz ${ }^{1,2}{ }^{(D}$, Francisco J. Gallego ${ }^{2,4}$, \\ Juan Carlos López-Linares ${ }^{1}\left(\mathbb{D}\right.$, Paloma Manzanares ${ }^{5}(\mathbb{D})$ and Eulogio Castro ${ }^{1,2}(\mathbb{D}$ \\ 1 Department of Chemical, Environmental and Materials Engineering, Campus Las Lagunillas, \\ Universidad de Jaén, 23071 Jaén, Spain; dicg0001@red.ujaen.es (D.C.); eruiz@ujaen.es (E.R.); \\ clinares@ujaen.es (J.C.L.-L.); ecastro@ujaen.es (E.C.) \\ 2 Centre for Advanced Studies in Earth Sciences, Energy and Environment (CEACTEMA), \\ Campus Las Lagunillas, Universidad de Jaén, 23071 Jaén, Spain; fgallego@ujaen.es \\ 3 Centro Tecnológico Nuevo Jaén, Instituto de Innovación, Ciencia y Empresa, \\ Ctra de Madrid Km 332, 23009 Jaén, Spain; teresamartinez@institutodeinnovacion.es \\ 4 Department of Graphic Engineering, Design and Projects, Campus Las Lagunillas, Universidad de Jaén, \\ 23071 Jaén, Spain \\ 5 Biofuels Unit, Renewable Energies Division, CIEMAT, Avda., Complutense 40, 28040 Madrid, Spain; \\ p.manzanares@ciemat.es \\ * Correspondence: iromero@ujaen.es
}

Citation: Cardoza, D.; Romero, I.; Martínez, T.; Ruiz, E.; Gallego, F.J.; López-Linares, J.C.; Manzanares, P. Castro, E. Location of Biorefineries Based on Olive-Derived Biomass in Andalusia, Spain. Energies 2021, 14, 3052. https://doi.org/10.3390/ en14113052

Academic Editor: Antonio Zuorro

Received: 22 April 2021

Accepted: 21 May 2021

Published: 25 May 2021

Publisher's Note: MDPI stays neutral with regard to jurisdictional claims in published maps and institutional affiliations.

Copyright: (C) 2021 by the authors. Licensee MDPI, Basel, Switzerland. This article is an open access article distributed under the terms and conditions of the Creative Commons Attribution (CC BY) license (https:/ / creativecommons.org/licenses/by/ $4.0 /)$.

\begin{abstract}
A biorefinery integrated process based on lignocellulosic feedstock is especially interesting in rural areas with a high density of agricultural and agro-industrial wastes, which is the case for olive crop areas and their associated industries. In the region of Andalusia, in the south of Spain, the provinces of Jaén, Córdoba and Seville accumulate more than $70 \%$ of the olive wastes generated in Spain. Therefore, the valorisation of these wastes is a matter of interest from both an environmental and a social point of view. The olive biorefinery involves a multi-product process from different raw materials: olive leaves, exhausted olive pomace, olive stones and olive tree pruning residues. Biorefinery processes associated with these wastes would allow their valorisation to produce bioenergy and high value-added renewable products. In this work, using geographic information system tools, the biomass from olive crop fields, mills and olive pomace-extracting industries, where these wastes are generated, was determined and quantified in the study area. In addition, the vulnerability of the territory was evaluated through an environmental and territorial analysis that allowed for the determination of the reception capacity of the study area. Then, information layers corresponding to the availability of the four biomass wastes, and layers corresponding to the environmental fragility of the study area were overlapped and they resulted in an overall map. This made it possible to identify the best areas for the implementation of the biorefineries based on olivederived biomass. Finally, as an example, three zones were selected for this purpose. These locations corresponded to low fragility areas with a high availability of biomass (more than 300,000 tons/year) in a $30 \mathrm{~km}$ radius, which would ensure the biomass supply.
\end{abstract}

Keywords: olive-derived biomass; biorefinery; geographic information systems, GIS; environmental fragility

\section{Introduction}

The introduction of renewable energies in the energy matrix has entailed a key advance at a global level to move away from the current fossil fuels-based economic system. The contribution of different renewable sources to energy consumption has been increasing steadily over the last decades worldwide. Thus, according to IRENA [1], in 2019, global renewable generation capacity amounted to $2537 \mathrm{GW}$, which represents an increase of $7.4 \%$ compared to the previous year. In Europe, the renewable energy capacity in that year accounted for $23 \%$ of the global share, 573 GW. The European Union has set new goals 
to be attained by 2030 in order to boost its position as a global leader in renewables, and also to help in meeting its emissions' reduction commitments under the Paris Agreement. The recast Renewable Energy Directive 2018/2001/EU [2] sets a new binding renewable energy objective for 2030 in the EU of not less than 32\%, including new supplies, to allow for self-consumption of renewable energy, an enlarged 14\% target for the contribution of renewable fuels in transport by 2030 and reinforced criteria for warranting bioenergy sustainability. These recent goals of the European Union in renewable energies aim at contributing to reaching the EU's objective to be climate-neutral by 2050 - an economy with net-zero greenhouse gas emissions. Precisely to protect and boost the 2050 climateneutrality target, the European Commission proposed, on 4 March 2020, the first European Climate Law. All these objectives are at the heart of the European Green Deal Action Plan, approved at the end of 2019, to face the challenges that the fulfilment of the goals assumed by world leaders in the 2030 Agenda for Sustainable Development involve [3].

Among the different renewable resources, biomass is a primary source for the production of energy and fuels due to characteristics such as continuous supply, extensive availability, easy accessibility and production potential. Regarding its contribution to global energy consumption, bioenergy contributed an estimated $12 \%$ to total final energy consumption in 2018, according to the Renewables 2020 Global Status Report, EN21 [4]. This figure includes the traditional use of biomass, burned for heating and cooking in simple and inefficient fires or stoves in developing and emerging economies. This is the highest share of the global energy supply of all renewable energy resources, providing energy for heating and transport, and also for electricity. Within the EU, biomass constitutes the main renewable energy source, contributing in 2018 to more than $58 \%$ of the energy consumption from all renewable energy sources. Bioenergy's main use is for heat $(74.2 \%)$, followed by electricity (13.4\%) and biofuels (12.5\%) [5].

Regarding biomass supply for bioenergy applications, a large variety of biomass feedstock materials exist that could be used for this purpose, all of which have been widely explored [6]. They mostly consist of currently cultivated crops, such as starchy and oleaginous crops; dedicated biomass crops, such as woody or herbaceous crops; agricultural residues, agro-food or urban wastes; and residues from forest clean-up operations and the wood processing industry.

Among the different biomass feedstocks, the lignocellulosic residues generated in agricultural crop management show great potential for utilization, since they are generated in large amounts and, in many cases, their disposal involves environmental concerns. Those agricultural residues, when produced in a concentrated way around localized areas, present a significant advantage from the point of view of the collection and transport activities related to specific biomass applications. In this respect, a good example is that of olive tree (Olea europaea) cultivation. The olive crop is an important economic activity, particularly in Mediterranean countries, which generates vast amounts of agricultural residues through annual olive tree pruning. At a global level, in 2019, 10,578,246 hectares of olive tree were cultivated according to Food and Agriculture Organization of the United Nations statistics [7], with Spain accounting for close to $25 \%$ of the total cultivated area, with 2,601,900 hectares. In Spain, the Andalusia region accounts for about $57-60 \%$ of total area of olive tree crop [8].

In olive tree cultivation, olive tree pruning waste (OTPW) is generated in a pruning operation carried out every two years, once fruit harvesting has been performed. It is composed of leaves, thin branches, and thick branches or wood (about 25, 50 and 25\%, respectively). These percentages can vary with tree age, production and/or regional pruning habits. While OTPW constitutes a major biomass residue originating from the crop cultivation, the olive oil industry generates several residues or by-products that can be considered as interesting lignocellulosic biomass feedstocks for energy applications (Figure 1). Olive pomace is a major by-product of the olive oil industry, and its composition changes depending on the production process used: three or two phases. In the three-phase system, water is added to the paste, which is then separated into a solid (olive pomace), 
an oily phase and a water phase. Due to the large amounts of wastewater generated in this process, and the problems encountered in advancing an efficient treatment technology that allows minimizing disposal problems, a two-phase process has been developed. This system, which is now broadly used in Spain, is basically the same process as the threephase system, but without adding water to the initial olive mash. Thus, this system only produces an aqueous solid residue (called also olive pomace) as a main waste, together with the olive oil. Nowadays, in Spain, olive pomace is treated in specific industries to extract the residual oil, i.e., the "pomace oil", after drying, generating a solid residue called "exhausted olive pomace" (EOP). EOP is formed by exhausted pulp, skin, seeds and stones, and has a high lower calorific value (about $3668 \mathrm{kcal} / \mathrm{kg}$, with 10\% moisture), which makes EOP a very interesting residue to be used as solid fuel $[9,10]$. Moreover, olive mill leaves (OML) are generated in the olive oil production facility (olive mills), as leaves have to be separated from the olives in the first phases of the olive oil production process (cleaning/washing step). OMLs have a lower calorific value of around $2360 \mathrm{kcal} / \mathrm{kg}$, with a moisture percentage of about 37\% [11]. Another interesting by-product associated with olive tree cultivation is olive stones (OS). Even though they can also be generated in the table olive industry, they are mainly obtained as small particles in olive mills once oil is separated, although a minor part can be removed from olive pomace in olive pomace oil extracting industries. Like EOP, OS also has low moisture (around of 13\%) and a high lower calorific value (about $3755 \mathrm{kcal} / \mathrm{kg}$ ) [11,12].

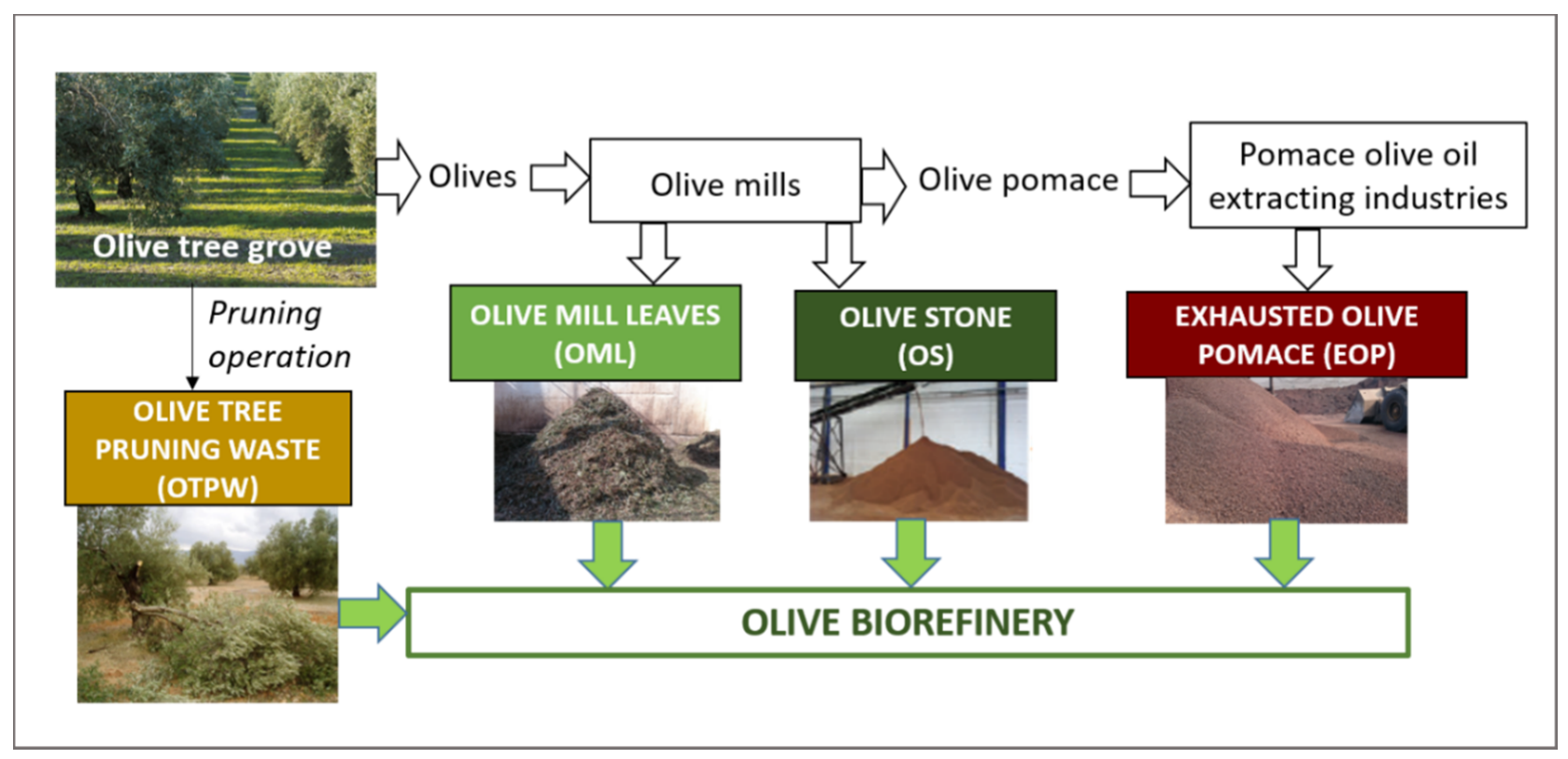

Figure 1. Generation of raw materials for olive-biomass-based biorefinery.

The biomass residues related to the olive oil industry, such as as those described above, as well as many others lignocellulosic biomass feedstocks, have been considered in a first approach for energy production in the form of solid fuels for heat and electricity production, or liquid biofuels as bioethanol for the transport sector. However, nowadays, new opportunities are emerging for integrating bioenergy applications within the biorefinery concept aimed at optimising the use of biomass resources and maximizing the production of bio-based products from lignocellulosic biomass. The basis of a biorefinery system is a new and efficient way to utilise available biomass resources for the synergetic production of power, heat and biofuels, together with other high value-added bio-based products, with application in diverse markets such as food, feed, pharmaceuticals, chemicals and materials. The biorefinery approach is considered a key strategic element to enhance the emergent bioeconomy by providing a wide range of products from a broad spectrum of biomass feedstocks in order to fulfil the diverse demands of society [13]. 
In the particular case of the biomass residues generated around the olive oil industry, previous research work carried out by the authors has shown the feasibility of efficiently using OTPW [14], EOP [9] and OS [15] as feedstocks to obtain bioethanol through a biochemical conversion process based on pretreatment, enzymatic hydrolysis and fermentation. Moreover, it has been proven that other chemicals and value-added products such as hydroxytyrosol, tyrosol, oleouropein, xylitol, mannitol and flavonoids, among others, can also be produced from those feedstocks in an integrated way with bioethanol $[11,16]$. Thus, taking into account the important contribution of Andalusia to olive tree cultivation, as well as the consolidated agro-industrial structure associated with the production of olive oil in this region, the implementation of biorefineries capable of valorising the residual biomass generated by this sector appears to be a promising option. It would mean a way to boost the bioeconomy in the region by promoting industry development using local resources, generating added value and creating employment.

For a successful biorefinery system, it is essential to determine the most adequate size and location for the plant, taking into account the biomass availability in the selected geographical zone. It is also necessary to approach other issues related to logistic practices to set up and start the operation of the plant for the establishment of biorefineries [17].

Regarding the location of the biorefinery, it is crucial to take into account the existence of protected areas, archaeological sites and the cultural heritage in the selected zone. In general, the location of all those areas where the biorefinery cannot be located for conservation reasons is key from the perspective of environmental preservation. Additionally, other types of issues different to those related to the environment should also be considered, such as the contribution of the biorefinery to economic and social growth in the region [16]. It is essential to find a balance between the protection and conservation of the environment and socio-economic development.

In this work, for the first time, the environmental fragility of the area with the highest olive-derived biomass concentration in Spain has been determined through both environmental and territorial analyses. Moreover, the provisioning capacity of raw materials to the biorefinery and logistical criteria, such as their proximity, are considered in order to select adequate locations for the implementation of the olive biomass-based biorefineries in Andalusia. Additionally, the environmental fragility of the study area, based on both territorial and environmental analyses, was determined using geographic information systems, software ArcGIS (10.2.1 (ESRI, Inc., Redlands, CA, USA). ArcGIS is a powerful tool used in the field of Geographic Information Systems (GIS) that is able to describe and explore partial data and integrate theory and methods to process spatial data. In addition, it is composed of spatial coordinates and professional attributes, being able to generate orthophoto maps once the data have been processed [18,19]. As a result of the whole study, three locations in areas with high biomass availability are chosen and proposed as biorefinery sites.

\section{Materials and Methods}

\subsection{Case Study}

This study was carried out in the region of Andalusia located in the south of Spain. Considering that more than $73 \%$ of the olive tree cultivation in Spain is concentrated in the provinces of Jaén, Córdoba and Seville, these provinces were selected as the study area for the location of biorefineries based in olive-derived biomass. The four main olive biomass resources of the olive oil sector were considered in this work: olive tree pruning waste (OTPW), olive mill leaves (OML), exhausted olive pomace (EOP) and olive stones (OS). The geographical location and availability of these wastes was determined.

\subsection{Biomass Supply}

Information data of olive tree crop area, production of olives in the mills and production of olive pomace in the extracting industries corresponded to average values of three seasons, 2012-2013, 2013-2014 and 2014-2015. The generation of OTPW was estimated 
from crop area. Nevertheless, the amount of biomass generated by the olive tree crop (OTPW) is highly uncertain and ultimately depends on the cultivar variety, the slope of the land and whether the crop is irrigated or rainfed [20]. According to Manzanares et al. [8], the crop area was classified in four categories: (i) areas with irrigation and slope $>10 \%$, (ii) irrigation and slope $<10 \%$, (iii) non irrigation and slope $<10 \%$ and (iv) non-irrigation and slope $>10 \%$. Additionally, the annual amount of OTPW was estimated per hectare, taking into account the crop classifications of $1.6 \mathrm{t}$ for categories (i) and (iii), 1.7 for category (ii) and $1.4 \mathrm{t}$ for category (iv). These indexes were used to estimate the production of OTPW in this work. Areas with a slope of $>20 \%$ were discarded due to the difficulties associated with the collecting of olive tree pruning wastes [20].

The Spanish Agency of Information and Food Control (AICA) of MAPAMA (Ministry of Agriculture, Fishing and Food) [21] supplied the necessary information for the geographical location of the olive mills and olive pomace-extracting industries, together with the amounts of olives and olive pomace processed in these industries, respectively. These production data allowed for the estimation of the amount of biomass wastes generated in these industries.

Concerning the OML generated during the cleaning of olives in the mills, their production was evaluated from the number of olives processed in the mills of the study area, considering an estimation index of $6.59 \mathrm{t}$ OML per $100 \mathrm{t}$ olives processed [8]. Likewise, the generation of the EOP was estimated based on the amount of olive pomace processed in the extracting industries, using a ratio of $25 \mathrm{t}$ of EOP per $100 \mathrm{t}$ of olive pomace [8].

\subsection{Methodology Description}

\subsubsection{Map Building}

GIS information was used to build the maps on which the optimal location of biorefineries was based. GISs are very useful tools in environmental studies for spatial information analysis, and their use by professionals is growing in several fields [22]. This information was processed and managed by means of ESRI's ArcGis software products, mainly through the ArcMap application. Different types of geographic information shapefiles were used in the construction of the maps with the ArcMap application from ArcGis. The shapefile format is a geospatial vector data format that contains all the geometric and spatial information of the objects (the information related to the shape and size) and the index of the geometric entities according to their nature (that is, a different aspect if the geometry is a road, terrain areas, geographic locations, etc.). This allows ArcGis to process and treat each element correctly, giving attributes and allowing for consistent processes according to the type of geometry. In addition to geometric and spatial information, shapefile format stores the attributes that the geometries may contain (such as name, identification number, area, length, $X Y$ coordinates, etc.), and the geographical location of each object is to be positioned correctly, which is especially important when some objects overlap each other (for example, a road above a geographical area).

A schematic diagram of the different steps of the map building process is depicted in Figure 2, and briefly described below.

All maps correspond to the study area. The first step in the building of the maps is the construction of the vectorized polygons corresponding to the study area that makes up the base layer on which the rest of the geographical information will be superimposed (roads, bodies of water, land uses, etc.). It is important that all the layers used have the same geographic coordinate system; in this case, the ETRS89 system (European Terrestrial Reference System 1989) was used. The regional government, Junta de Andalucía, offers georeferenced shapefiles at the provincial level throughout Andalusia. Since the provinces that make up the study area are Jaén, Córdoba and Seville, a new layer formed only by these three provinces was created from the layer that includes all of Andalusia. 


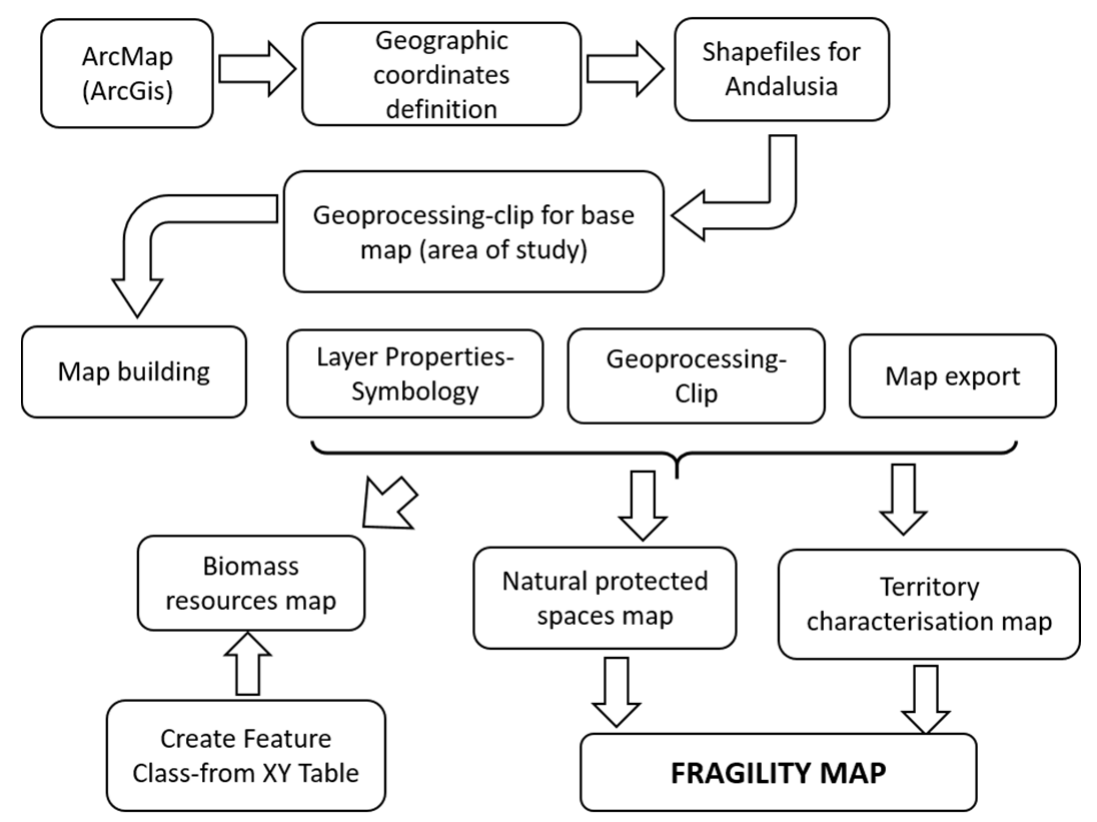

Figure 2. Schematic methodological approach to determine the fragility maps.

\subsubsection{Building of the Biomass Source Location Map}

As the biomass sources corresponding to OML and OS come from oil mills and EOP from extracting industries, it was necessary to geographically locate each one of these plants. AICA registered, within the study area, 582 oil mills and 17 extracting industries, accompanied by their XY geographic coordinates. These coordinates were used by the ArcMap application to locate the oil mills and extractors within the map of the study area, and each location was stored as a point-like geometric entity within two shapefiles (one for oil mills and the other for extractors), accompanied by its list of attributes with relevant information such as the amount of biomass.

Concerning the pruning residues, another source of biomass taken into account, the geographical locations and the area of all the areas of origin (agricultural plots) were identified. The information on the cultivation area was provided by the Agricultural Parcels Geographic Information System (SIGPAC). These data were contained in a polygon-type shapefile and with an attribute table that included the area of each registered parcel.

To give a better reference to the location of biomass sources, access roads were also added, which consisted of three categories: highways, main and secondary roads. Each path was contained in a line-type shapefile.

\subsubsection{Protected Areas and Characterisation of the Territory: Map Building}

Protected natural areas in a territory enjoy a protection system according to regional and state regulations, or international agreements. The purpose of declaring a territory a protected natural space is the conservation of its natural values and the promotion of its sustainable development. The concept of protected natural area includes national parks, natural parks, geoparks, natural monuments, natural reserves and protected landscapes, among others. Natural heritage refers to natural features, geological and physiographical formations and delineated areas that constitute the habitat of threatened species of animals and plants and natural sites of value from the point of view of science, conservation or natural beauty. Another important figure in the protected natural spaces of the study area is the forest. According to the Spanish forestry legislation, the term forest is broad and includes not only woodlands but also scrublands and grasslands. Thus, Andalusian forests include very heterogeneous forest formations, both from the point of view of their composition and their structure.

Concerning the territorial analysis, different categories were considered: woodland, scrubland, grassland, wetland, field crop and urban areas. It should be noted that the 
category of wetlands extends to all perennial water bodies in a territory, including lakes and lagoons, salt marshes and marshes. The farmland category includes (i) arable crops such as cereals or rice, (ii) greenhouses and woody crops such as fruit trees, olive trees and vines.

The information for these maps was retrieved from REDIAM (Environmental Information Network of Andalusia), Junta de Andalucía [23]. The protected natural areas consist of different layers, depending on the protected areas they contain; many of the areas cover more than one province, sometimes causing part or all of its territory to be outside the area of interest. This same situation occurred with the soil characterisation map. To solve this problem, the clip tool in ArcMap was used once again to cut the different layers of information based on the study area.

\subsubsection{Environmental Fragility Map}

The fragility map was established based on the susceptibility of a particular area to negative impacts caused by human activities, in this case a biorefinery. This susceptibility was determined according to information corresponding to i) the protected natural spaces and ii) the characterisation of the land (use and land cover). It can be note that the hydrographic network was also geographically located and considered to evaluate the environmental fragility in the study area. Therefore, the fragility map was made by overlapping these layers of information (protected natural spaces and characterisation of the terrain). The geographic information was accessed through the Environmental Information Network of Andalusia (REDIAM) [23] and managed by the Andalusian Government, whose information is publicly available.

In this work, different degrees of protection were considered in the assessment of environmental fragility, which was classified into four categories (Table 1).

Table 1. Classification of environmental fragility.

\begin{tabular}{lcc}
\hline Fragility & Land Use and Cover & * Area (\%) \\
\hline Very high & Protected areas & 19 \\
High & Natural vegetation, hydrographic network and livestock trails & 35 \\
Medium & Croplands & 41 \\
Low & Urban and industrial areas & 5 \\
\hline * Referred to the study area. &
\end{tabular}

Very high fragility areas correspond to the sites most vulnerable to the introduction of new land uses. They correspond to protected areas to ensure their conservation and their natural values. At the other end of the scale, high reception capacity areas are found; these low environmental fragility areas correspond to urban and industrial uses. The areas in this category would be capable of introducing new land uses without significant disruptions. Areas named 'high' and 'very high environmental fragility areas' must be discarded for the implementation of industrial activities.

\subsubsection{Site Selection}

Once the theoretical biomass potential was quantified in the study area, zones of the olive tree fields with slopes higher than $20 \%$ were discarded, as indicated in Section 2.2. Then, the environmental fragility of the study area was determined through both territorial and environmental analysis. After that, information layers corresponding to the location of the four biomass resources considered in this work were overlapped with the information layers of the environmental fragility of the study area. The final purpose of this task was to know the environmental fragility of the areas with the highest olive-derived biomass concentrations. Logistical aspects such as the proximity of the biorefineries to the biomass resources were also considered as key factors for the economic viability of the installation. In this way, the most suitable areas for plant locations were identified according to all of this information. 


\section{Results and Discussion}

To achieve the objective of the work, this section is structured as follows: the biomass potential was first estimated, then the environmental and territorial analysis was performed to determine the environmental fragility of the territory. Finally, the combination of all the information allows the most suitable areas for biorefinery deployment to be located.

\subsection{Olive-Derived Biomass Availability}

The study covers an area of 2,753,085 hectares and it is worth highlighting that more than $42 \%$ is covered by olive tree crop [24]. Nevertheless, to evaluate the amount of OTPW generated, just 874,338 hectares of olive crop were considered after deducting the olive crops located in terrains with slopes higher than $20 \%$, as indicated in Section 2.2. The amount of OTPW generated annually during the pruning operation of olive trees was estimated according to the indexes indicated in Section 2.2. Thus, considering the area corresponding to each crop category, the annual availability of OTPW in the study area would be 1,330,833 tons. As can be appreciated, rainfed crops were identified as the majority and, therefore, they are the main suppliers, with a contribution of $78 \%$ (Table 2 ).

Table 2. Availability of olive tree pruning waste (OTPW) depending on the cultivation category.

\begin{tabular}{ccc}
\hline Category & Area (ha) & OTPW (t) \\
\hline Irrigation and slope $>10 \%$ & 61,176 & 97,882 \\
Irrigation and slope $<10 \%$ & 113,982 & 193,770 \\
Without irrigation and slope $<10 \%$ & 325,417 & 520,667 \\
Without irrigation and slope $>10 \%$ & 370,367 & 518,514 \\
\hline
\end{tabular}

The supply capacity of OML and OS from mills present in the study area was also assessed (Table 3). Based on the estimation ratio described in Section 2.2, a total amount of 227,503 t of leaves was determined, with Jaén and Córdoba being the main producers of this waste, accounting for more than $86 \%$ of the OML generated in the study area. Previous works determined that the provinces of Jaén and Córdoba would be capable of supplying a sufficient amount of olive mill leaves to a biorefinery based on this biomass [8].

Table 3. Supply capacity of biomass from olive mills and olive pomace-extracting industries located in the study area.

\begin{tabular}{cccc}
\hline & \multicolumn{2}{c}{ Olive Mills } & Extracting Plants \\
\cline { 2 - 4 } & Olive Mill Leaves (t) & Olive Stones (t) & Exhausted Olive Pomace (t) \\
\hline Jaén & 118,408 & 179,678 & 319,226 \\
Córdoba & 76,284 & 115,757 & 530,246 \\
Seville & 32,811 & 49,789 & 64,584 \\
Total & 227,503 & 345,224 & 914,056 \\
\hline
\end{tabular}

Likewise, the amount of OS was determined considering that this part of the olive represents between 8 and 15\% of its weight [25]. In this work, an average content of 10\% stone in the olive has been considered, which means an annual production of 345,224 $\mathrm{t}$ of stones in the study area. Concerning EOP, the main waste generated in the olive pomaceextracting industries; the supply capacity from these facilities was estimated as 914,056 tons of EOP, to which Córdoba contributed 58\% (Table 3).

The province of Jaén was identified as the main producer of OML and OS because it accounts for the highest number of mills-321, according to AICA [21]. In contrast, the greatest production of EOP corresponds to the province of Córdoba that has six extraction plants, just like the province of Jaén but with a greater production capacity (Table 3).

Once the availability of both OML and OS generated in the olive mills, and EOP generated in the extracting industries, was estimated, these information layers were overlapped 
together with the information layer corresponding to olive tree crop fields (where OTPW is generated), resulting in an overall map showing the availability of the different olive biomasses in the study area (Figure 3).

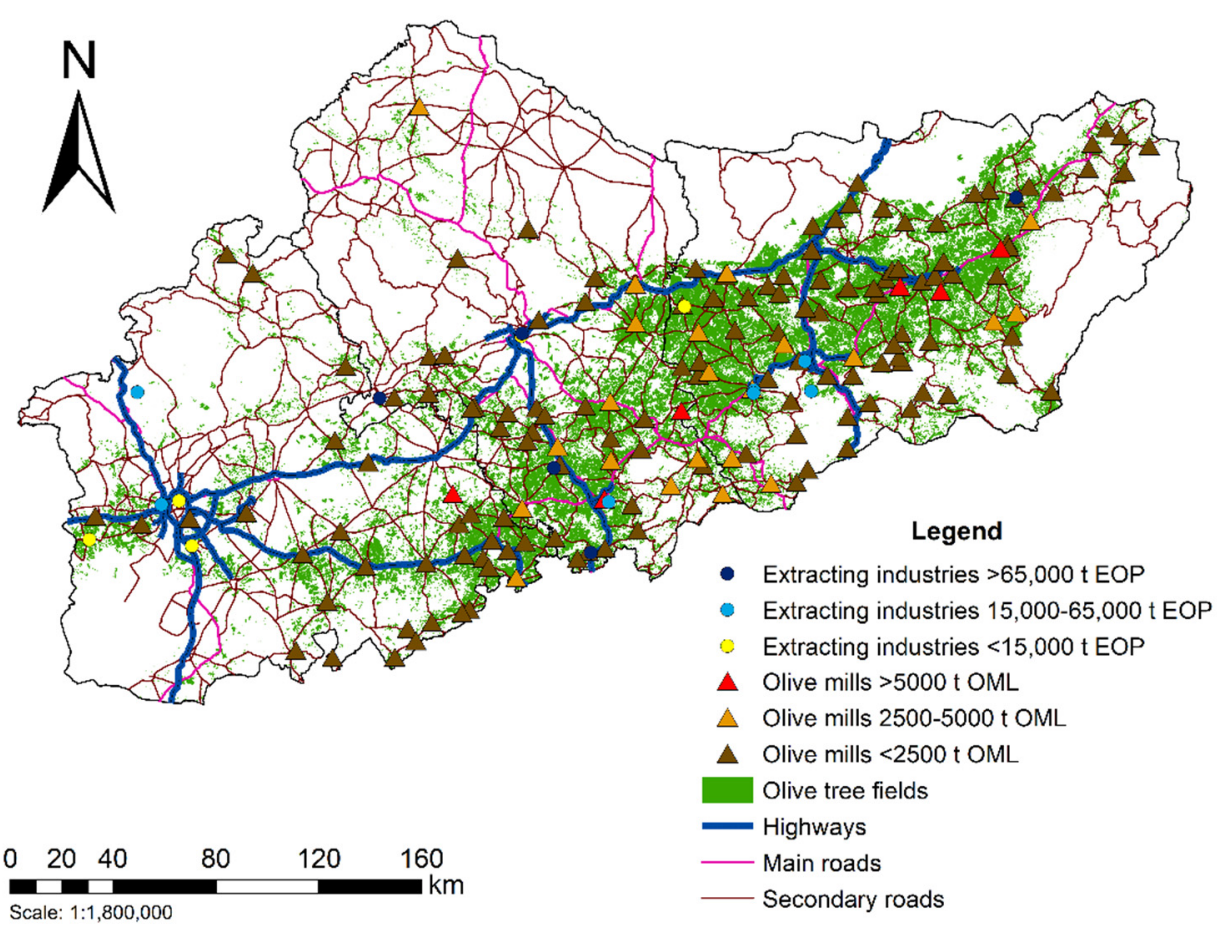

Figure 3. Geographical location of olive tree crops, olive mills and olive oil pomace-extracting industries.

The olive mills were located geographically on the biomass availability map and three groups were differentiated based on the amount of OML generated annually in each one of them (Figure 3). It should be noted that, although most of the OS is also obtained in these plants as a result of olive paste pitting, in this work, the production of OS was not taken into account to define the size of the mills. This can be explained by the distribution between olive and pomace pitting, which can be variable each season depending on market aspects, and this determines whether the EOP is mainly generated in the mills or in the extracting industries.

Likewise, the extracting industries that would supply the EOP were geographically located. These facilities were classified into three groups according to the amount of EOP generated, which is directly related to the amount of olive pomace processed by them.

This map also includes the geographical locations of road and highway networks in the study area (Figure 3). A high accessibility to mills and extracting industries can be observed, and therefore to OML, OS and EOP generated by them, which would facilitate the biomass transportation to the biorefineries.

\subsection{Environmental and Territorial Analysis}

The environmental analysis of a territory implies identifying the geographical location of its protected natural areas, natural heritage, forests and livestock trails. The information corresponding to all these environmental elements was combined to obtain the protected natural site map in the study area (Figure 4).

The protection of the environment is crucial for achieving sustainable development, and this implies the conservation and protection of especially vulnerable elements and areas. Andalusia accounts for 310 protected areas, with an area of 2.9 million hectares, which corresponds to $30 \%$ of its total area [26]. It can be noted that 704,423 hectares correspond to the study area where the Natural Park of Cazorla, Segura y Las Villas stands out with 209,763 hectares, the largest protected area in Spain, and the Geopark of North 
Mountain of Seville, with 177,484 hectares. In addition, Andalusia has the most extensive livestock trail network in Spain, of 34,082 km [26]. Important bird areas (IBAs) stand out within the natural heritage as priority sites for bird conservation, with an extension of 259,297 hectares in the study area. In the Andalusian region, is worth noting that the forests play an essential role in biodiversity conservation due to the great variety of habitats they contain. The area covered by forest in the study area is 384,607 hectares, with the majority being in the province of Jaén [23].

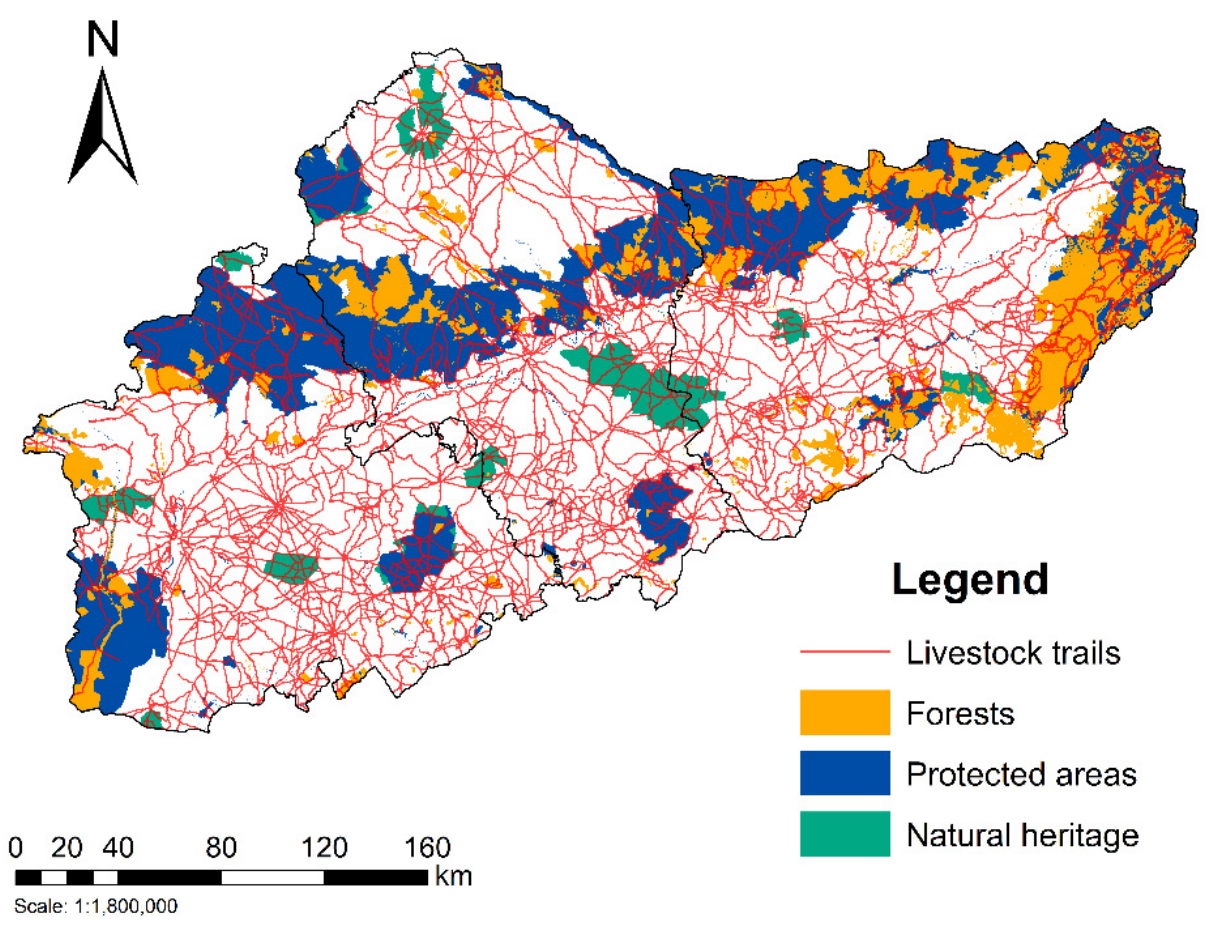

Figure 4. Map of protected natural areas.

The information layers corresponding to all these components identified in the study area were overlapped to build a map of the protected natural spaces (Figure 4).

In addition to identifying and geographically locating the protected areas, it is necessary to know the land cover and use in the study area. This information will facilitate the selection of the best geographic locations for the implementation of the olive biorefineries. According to the classification established in Section 2.3.3, in the cropland category, olive tree cultivation makes up the main woody crop in Andalusia, and also in the study area. In this work, the category of urban territory includes residential, industrial and mining uses, as well as bare lands or lands with vegetation covering less than $20 \%$.

These information layers were combined, as described in Section 2.3.3, to build the map of the territorial analysis in the study area (Figure 5). As can be observed, most of the area is covered by farmlands, more than 2 million hectares, which correspond to $73 \%$ of the study area. In addition to olive trees, cereal crops stand out in the study area, mainly in the province of Seville, together with rice and citrus fruits [23].

\subsection{Environmental Fragility of the Study Area}

The fragility of a territory determines its capacity for the introduction of new land uses. The study of the environmental vulnerability of a territory allows for the identification of its most sensitive areas, which must be discarded for the implementation of industrial activities [22]. In this work, the capacity of the study area for introducing the olive biorefineries was evaluated by determining its environmental fragility. This parameter was evaluated based on the environmental and territorial analysis of the study area. In addition, the hydrographic network in this area, which corresponds to the hydrographic network of the Guadalquivir River that crosses the three provinces in the study, was 
geographically located and considered to determine the environmental fragility of the territory (map not shown). The procedures for environmental fragility mapping described in Section 2.3.4 were applied to the study zone. The information layers obtained from both environmental and territorial analyses were overlapped to obtain the fragility map of the study area. (Figure 6). Environmental fragility maps are essential tools for quantifying environmental sensitivity and for understanding the relationship between human activities and environmental quality [27].

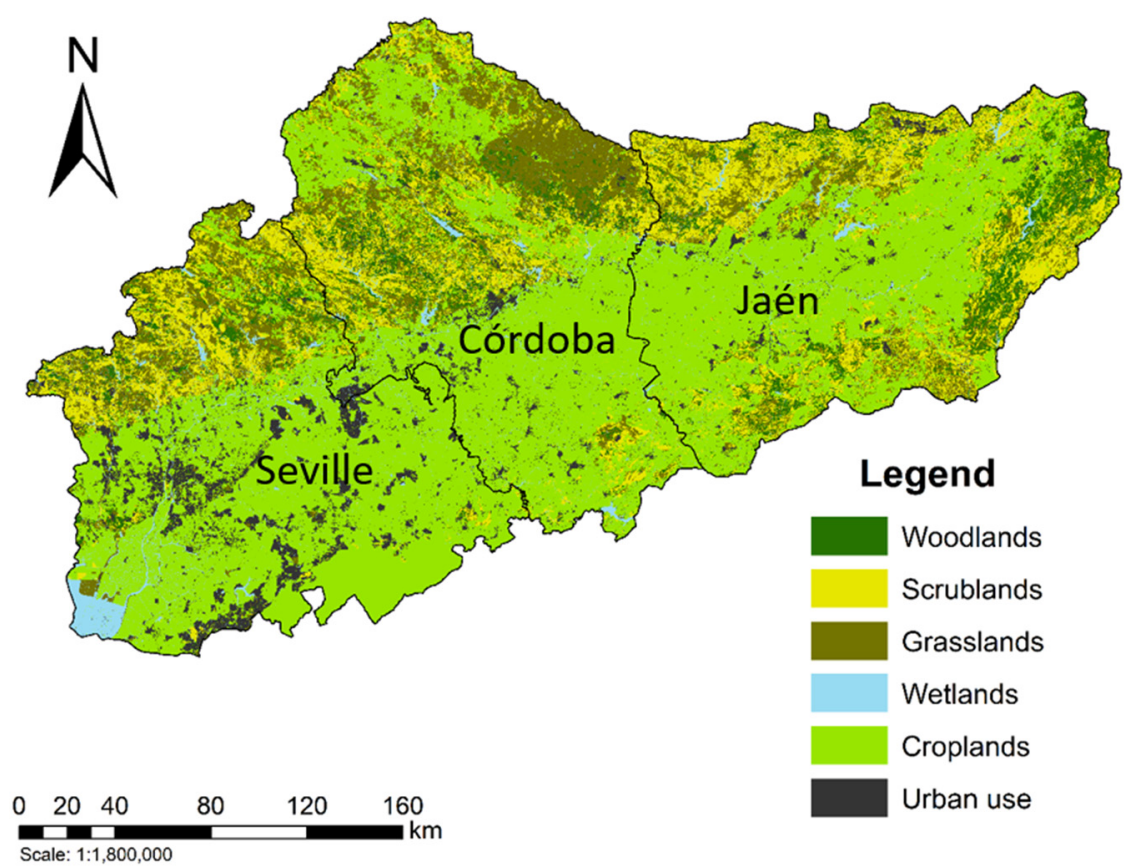

Figure 5. Territorial analysis map: land cover and use.

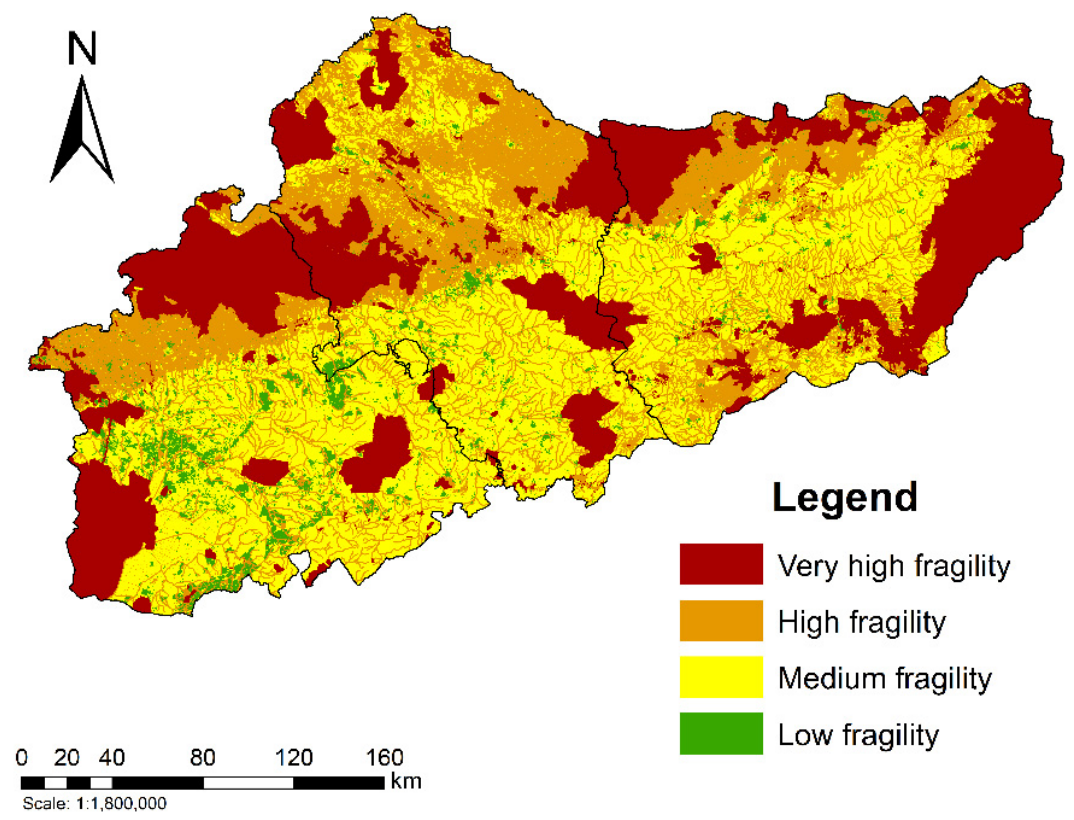

Figure 6. Environmental fragility map of the study area.

This study showed the areas with the lowest environmental fragility that correspond to the areas of highest reception capacity. It is worth highlighting that only $19 \%$ of the study area was identified as having very high fragility (Table 2), coinciding mainly with protected natural areas, whilst the majority of the study area is labeled as medium and 
high fragility areas. However, only $5 \%$ of the territory has low environmental fragility, corresponding to urban use. Therefore, only these latter areas should be considered as possible zones for the implementation of the olive-derived biomass biorefineries from an environmental and territorial point of view. Nevertheless, logistical and technical criteria were also taken into account.

\subsection{Proposed Areas for the Implementation of Biorefineries Based on Olive-Derived Biomass}

Environmental protection in a territory implies the strict vigilance of possible new land uses. Thus, the implementation of new activities in a territory requires a previous study that assesses its reception capacity. Nevertheless, in addition to environmental and territorial matters, logistic aspects such as the supply chain for biomass feedstock for energy production, or other uses, must be considered [28].

In this work, aspects related to the availability and the supply of biomass to the biorefinery are considered crucial for selecting the best locations for these industrial plants that will use olive-derived biomass as raw materials. Thus, once the vulnerability of the study area was evaluated and its environmental fragility had been determined, these information layers (Figure 6) were overlapped with the biomass availability information layers (Figure 3). As a result, a complete map where all biomass sources were geographically located and the reception capacity of the territory was defined was obtained (Figure 7). This map made it possible to determine the most suitable areas to locate olive biorefineries. For this task, only the areas corresponding to industrial zones where olive mills and extracting industries are located were considered as suitable areas for the implementation of biorefineries. In addition, these areas coincided with the main olive biomass concentration. Thus, areas corresponding to other land uses were discarded for this purpose.

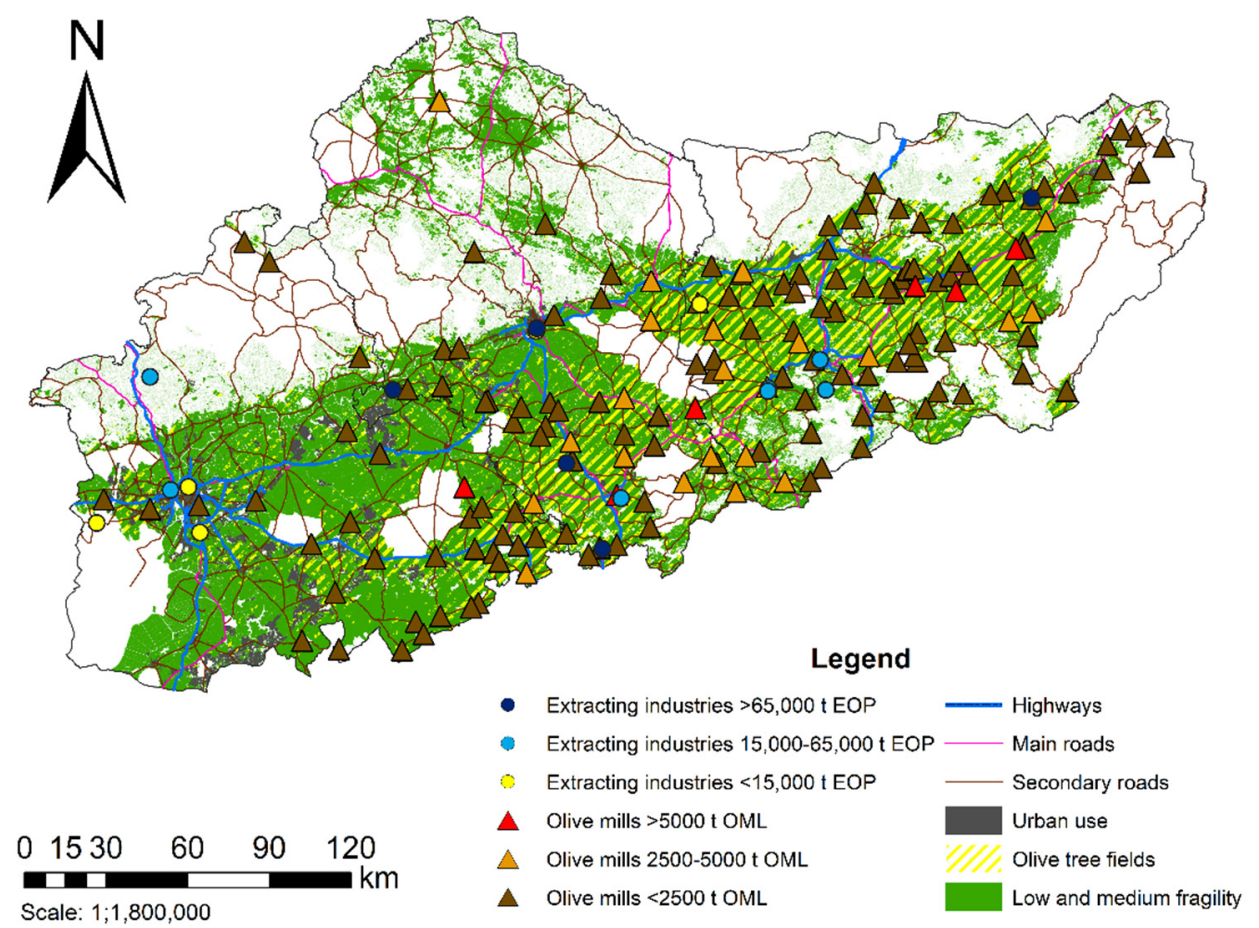

Figure 7. Complete map, including the olive biomass available overlapped with the environmental fragility of the study area.

The evaluation of the supply chain is essential to ensure the availability of raw materials in the biorefinery [29]. In the case of olive-derived residues, as these are seasonally generated, the concept of multi-feedstock biorefineries is especially interesting because it would guarantee their supply capacity throughout the year. High amounts of olive-derived biomass are required to ensure its supply by integrating different feedstock materials. How- 
ever, it is important to consider a maximum radius around the biorefinery that guarantees acceptable logistical costs because the transportation costs can be an important part of the processing costs, especially in small-scale processing [30]. In this sense, Susmozas et al. [31] fixed a radius of $10 \mathrm{~km}$ for collecting OTPW around the biorefinery. Gutiérrez et al. [32] placed a radius of $100 \mathrm{~km}$ around a biorefinery based on agricultural and forest wastes, including OTPW, also located in the region of Andalusia. Previous works have considered a maximum radius of $35 \mathrm{~km} \mathrm{[33]} \mathrm{and} 50 \mathrm{~km}$ [20] around the plants based on OTPW. In this work, $30 \mathrm{~km}$ was fixed as the maximum radius around the olive biorefineries.

Considering all these requirements, three sites with high availability of biomass resources in low fragility areas were selected as suitable locations for the implementation of these industrial facilities (Figure 8). As can be observed in the map, the areas with the highest biomass availability coincided with low and medium fragility areas. Medium fragility areas correspond to olive tree fields and low fragility areas correspond to industrial areas where olive mills and extracting industries are located. In these industrial zones (low fragility areas) surrounded by olive tree fields (medium fragility areas), three alternatives of geographic locations (A, B and C) were proposed for the implementation of the olive biorefineries. The three locations chosen included several small and medium-sized olive mills and at least one medium or large extracting industry. This fact is related to the possibility of locating the biorefinery as a process integrated with the extracting industries, which are considered to be facilities with greater technological developments than olive mills.

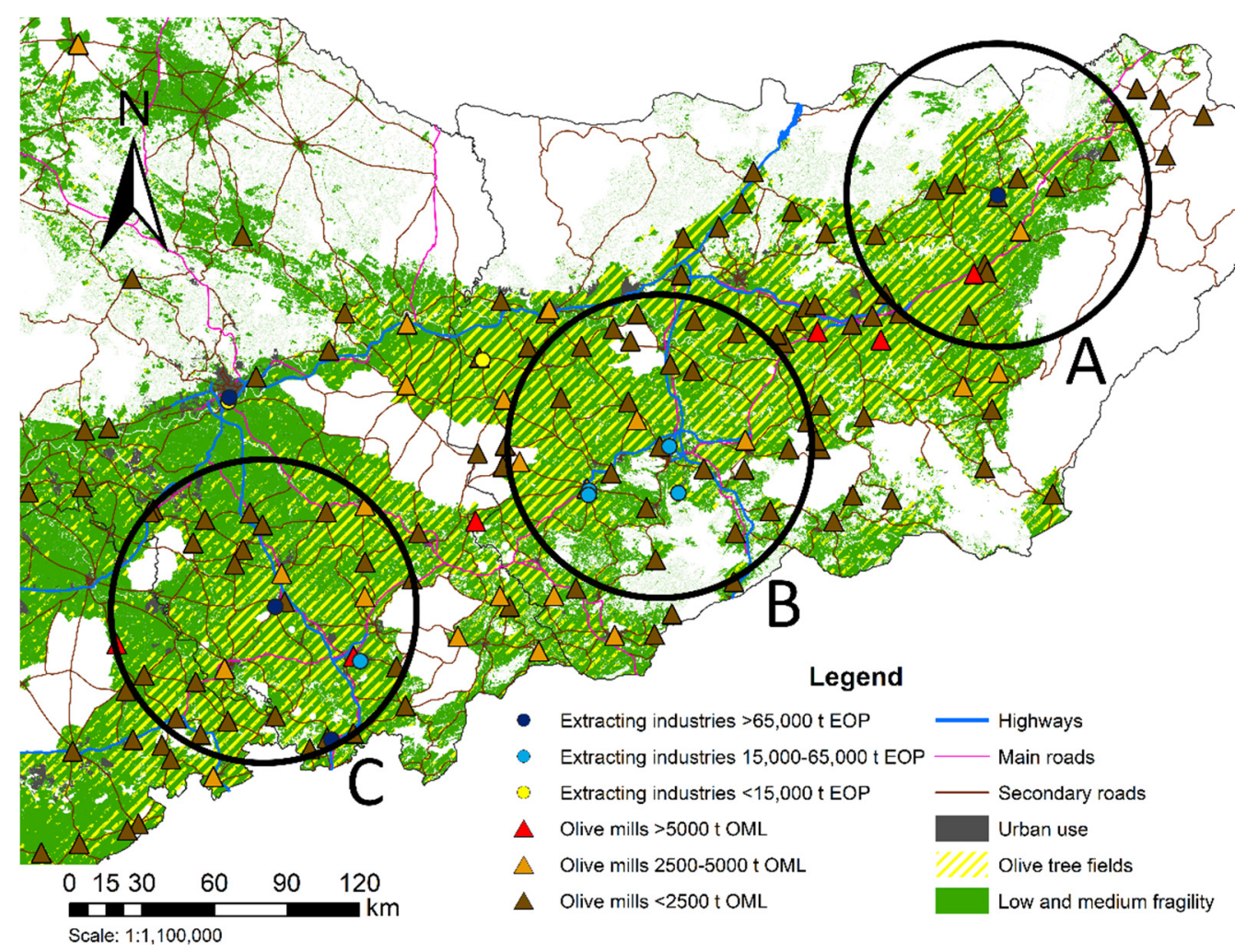

Figure 8. Selected locations for the implementation of olive biorefineries.

Finally, an estimation of the amount of each type of biomass available for the three selected locations was determined (Table 4). The biorefineries in those locations would have more than 300,000 t of biomass, even exceeding 500,000 $\mathrm{t}$ at location C. This would allow the implementation of various small-scale or a large-scale biorefineries, although the determination of the process scale of the olive biorefinery is not the aim of this work. Susmozas et al. [31] defined a small-scale integrated biorefinery with a processing capacity of 40,000 t OTPW/year. Nevertheless, the definition of large or small-scale biorefineries 
can be related to the economic feasibility of the process, although this can be controversial due, in part, to whether the reference used is the raw material or the product/s [29].

Table 4. Olive biomass availability for the biorefineries in the selected areas.

\begin{tabular}{cccc}
\hline \multicolumn{2}{c}{ Option A } & \multicolumn{2}{c}{ Biomass Amount (t) } \\
\hline Crop Fields & Option B & Option C \\
\hline Olive tree Pruning Biomass & & \\
\hline Non-irrigation and slope $>10 \%$ & 64,912 & 100,679 & 75,956 \\
\hline Non-irrigation and slope $<10 \%$ & 43,526 & 69,553 & 109,101 \\
\hline Irrigation and slope $>10 \%$ & 8842 & 22,445 & 11,887 \\
\hline Irrigation and slope $<10 \%$ & 8912 & 25,275 & 29,824 \\
\hline Olive mills & & \\
\hline Leaves & 22,339 & 32,232 & 49,927 \\
\hline Olive stones & 33,898 & 48,910 & 75,762 \\
\hline Extracting industries & & & 174,373 \\
\hline Exhausted olive pomace & 124,333 & 186,057 & $\mathbf{5 2 6 , 8 3 0}$ \\
\hline Total & $\mathbf{3 0 6 , 7 6 3}$ & $\mathbf{4 8 5 , 1 5 1}$ & \\
\hline
\end{tabular}

As shown in Table 4, the main feedstock would be OTPW, with a contribution to the biorefinery feedstock supply higher than $40 \%$ in all selected zones. This agricultural waste could be used for sugar production or for bioethanol production by a biochemical process [34]. Likewise, these plants would have a high availability of EOP from the olive pomace-extracting industries that could be used as raw material for antioxidants [35], xylitol [10], lignin and sugar production [36,37]. The potential for the olive stones to produce highly concentrated xylose solutions [38], and the olive leaves to produce oleuropein [39], mannitol [40] and protein [41], has been reported. Susmozas et al. [31] evaluated the techno-economic feasibility of biorefineries based on OTPW to produce ethanol, power, xylitol and antioxidants using a bioconversion integrated process. In this work, the proposal of implementing multi-product biorefineries means the valorisation of the olive agricultural and agro-food wastes in the rural areas where they are generated through integrated processes to obtain bioenergy and renewable chemicals. This biorefinery strategy based on lignocellulosic wastes contributes to the development of the circular bioeconomy model in rural areas associated with olive tree crops, while considering environmental and territorial criteria.

\section{Conclusions}

The environmental and territorial analyses carried out in the study area made it possible to determine suitable sites for the location of a potential biorefinery based on olive derived biomass. These areas correspond to low environmental fragility zones and a high availability of olive biomass (>300,000 t/year) within a radius of $30 \mathrm{~km}$, which would guarantee a secure supply and acceptable transportation costs. This study can be considered as a preliminary study for the identification of the most suitable areas for installing olive biorefineries. Nevertheless, the location of the plants can be influenced by other environmental and socio-political factors, which could be considered in further research, together with a techno-economic evaluation. The valorisation of olive tree pruning waste, exhausted olive pomace, olive mill leaves and olive stones to produce biofuels and renewable chemical products thorough biochemical processes would mean a great opportunity to boost the regional development of a bio-based industry and promote employment generation in the zone. Moreover, the methodology used in this work could 
be applied to other rural areas with high availability of residual biomass as a key tool to support the development of biorefineries, thus contributing to the move towards a real bioeconomy-based society.

Author Contributions: Conceptualization, I.R. and E.R.; methodology, T.M.; software, D.C. and T.M. and F.J.G.; validation, E.R.; formal analysis, E.C.; writing-original draft preparation, J.C.L.-L. and D.C.; writing-review and editing, I.R.; supervision, E.C.; project administration, P.M., E.R. and I.R.; funding acquisition, P.M., E.R. and I.R. All authors have read and agreed to the published version of the manuscript.

Funding: This research was funded by Agencia Estatal de Investigación (MICINN, Spain) and Fondo Europeo de Desarrollo Regional, reference projects ENE2017-85819-C2-1-R and ENE2017-85819-C2-2-R.

Institutional Review Board Statement: Not applicable.

Informed Consent Statement: Not applicable.

Data Availability Statement: Not applicable.

Conflicts of Interest: The authors declare no conflict of interest.

\section{References}

1. IRENA. International Renewable Energy Agency. Available online: https://www.irena.org/ (accessed on 25 October 2020).

2. EU Parliament and Council Directive. 2018/2001 on the promotion of the use of energy from renewable sources (recast). Off. J. Eur. Union 2018, 328, 82-209.

3. Sikora, A. European green deal-Legal and financial challenges of the climate change. ERA Forum. 2021, 21, 681-697. [CrossRef]

4. REN21. Renewables 2020 Global Status Report (Paris: REN21 Secretariat); REN21: Paris, France, 2020; ISBN 978-3-948393-00-7.

5. ETIP Bioenergy. Bioenergy in Europe. 2020. Available online: https://etipbioenergy.eu/images/ETIP_B_Factsheet_ BioenergyinEurope_rev_feb2020.pdf (accessed on 30 November 2020).

6. Rasool, U.; Hemalatha, S. A review on bioenergy and biofuels: Sources and their production. Braz. J. Biol. Sci. 2016, 3, 3-21. [CrossRef]

7. FAOSTAT. Food and Agriculture Organization of the United Nations. 2021. Available online: http://www.fao.org/faostat/en/ \#data/QC (accessed on 2 March 2021).

8. Manzanares, P.; Ruiz, E.; Ballesteros, M.; Negro, M.J.; Gallego, F.J.; López-Linares, J.C.; Castro, E. Residual biomass potential in olive tree cultivation and olive oil industry in Spain: Valorization proposal in a biorefinery context. Span. J. Agric. Res. 2017, 15, e0206. [CrossRef]

9. López-Linares, J.C.; Gómez-Cruz, I.; Ruiz, E.; Romero, I.; Castro, E. Production of ethanol from hemicellulosic sugars of exhausted olive pomace by Escherichia coli. Processes 2020, 8, 533. [CrossRef]

10. López-Linares, J.C.; Ruiz, E.; Romero, I.; Castro, E.; Manzanares, P. Xylitol production from exhausted olive pomace by Candida boidinii. Appl. Sci. 2020, 10, 6966. [CrossRef]

11. Romero-García, J.M.; Niño, L.; Martínez-Patiño, C.; Álvarez, C.; Castro, E.; Negro, M.J. Biorefinery based on olive biomass. State of the art and future trends. Bioresour. Technol. 2014, 159, 421-432. [CrossRef]

12. Sánchez, P.; Ruiz, M.V. Production of pomace olive oil. Grasas y Aceites 2006, 57, 47-55. [CrossRef]

13. Hingsamer, M.; Jungmeier, G. Biorefineries. In The Role of Bioenergy in the Emerging Bioeconomy, 1st ed.; Lago, C., Caldés, N., Lechón, Y., Eds.; Elsevier: Amsterdam, The Netherlands, 2018; pp. 180-221.

14. Martínez-Patiño, J.C.; Romero-García, J.M.; Ruiz, E.; Oliva, J.M.; Álvarez, C.; Romero, I.; Negro, M.J.; Castro, C. High solids loading pretreatment of olive tree pruning with dilute phosphoric acid for bioethanol production by Escherichia coli. Energy Fuels 2015, 29, 1735-1740. [CrossRef]

15. Romero-García, J.M.; Martínez-Patiño, C.; Ruiz, E.; Romero, I.; Castro, E. Ethanol production from olive stone hydrolysates by xylose fermenting microorganisms. Bioethanol 2016, 2, 51-65. [CrossRef]

16. Serrano-Hernandez, A.; Faulin, J. Locating a biorefinery in northern Spain: Decision making and economic consequences. Socioecon. Plann. Sci. 2019, 66, 82-91. [CrossRef]

17. Kurian, J.K.; Raveendran, G.; Hussain, N.A.; Raghavan, G.S.V. Feedstocks, logistics and pre-treatment processes for sustainable lignocellulosic biorefineries: A comprehensive review. Renew. Sustain. Energy Rev. 2013, 25, 205-219. [CrossRef]

18. Al-Najjar, H.; Pfeifer, C.; Al Afif, R.J.; El-Khozondar, H. Estimated view of renewable resources as a sustainable electrical energy source, case study. Designs 2020, 4, 32. [CrossRef]

19. Wei, B.; Luo, J.; Maiga, Q. Application of ArcGIS spatia lanalysis technology insite selection of high way dump. West. China Commun. Sci. Technol. 2019, 7, 10-13.

20. Ruiz-Arias, J.A.; Terrados, J.; Pérez-Higueras, P.; Pozo-Vázquez, D.; Almonacid, G. Assessment of the renewable energies potential for intensive electricity production in the province of Jaén, southern Spain. Renew. Sust. Energ. Rev. 2012, 16, $2994-3001$. [CrossRef] 
21. MAPAMA. Anuario de Estadística Agroalimentaria. Ministerio de Agricultura, Alimentación y Medio Ambiente, Gobierno de España. 2014. Available online: https:/ / www.mapa.gob.es/es/estadistica/temas/publicaciones/anuario-de-estadistica/ (accessed on 11 December 2020).

22. Adami, S.F.; Coelho, R.M.; Chiba, M.K.; de Moraes, J.F.L. Environmental fragility and susceptibility mapping using geographic information systems: Applications on Ribeirão do Pinhal watershed (Limeira, state of São Paulo). Acta Sci. Technol. Mar. 2012, 34, 433-440. [CrossRef]

23. REDIAM (Environmental Information Network of Andalusia). Available online: http://www.juntadeandalucia.es/ medioambiente/site/rediam (accessed on 14 December 2020).

24. FEGA (Fondo Español de Garantía Agraria). Ministerio de Agricultura, Pesca y Alimentación. Available online: https:/ /sigpac mapa.gob.es/fega/visor/ (accessed on 22 January 2021).

25. Ruiz, E.; Romero-García, J.M.; Romero, I.; Manzanares, P.; Negro, M.J.; Castro, E. Olive-derived biomass as a source of energy and chemicals. Biofuels Bioprod. Biorefin. 2017, 11, 1077-1094. [CrossRef]

26. Junta de Andalucía. 2021. Available online: http://www.juntadeandalucia.es/medioambiente/site/portalweb (accessed on 10 February 2021).

27. Manfré, L.A.; Silva, A.M.D.; Urban, R.C.; Rodgers, J. Environmental fragility evaluation and guidelines for environmental zoning: A study case on Ibiuna (the Southeastern Brazilian region). Environ. Earth Sci. 2013, 69, 947-957. [CrossRef]

28. Suardi, A.; Bergonzoli, S.; Alfano, V.; Scarfone, A.; Pari, L. Economic distance to gather agricultural residues from the field to the integrated biomass logistic centre: A Spanish case-study. Energies 2019, 12, 3086. [CrossRef]

29. Serna-Loaiza, S.; García-Velásquez, C.A.; Cardona, C.A. Strategy for the selection of the minimum processing scale for the economic feasibility of biorefineries. Biofuels Bioprod. Bioref. 2019, 13, 107-119. [CrossRef]

30. Bruins, M.E.; Sanders, J.P.M. Perspective: Small scale processing of biomass for biorefinery. Biofuels Bioprod. Bioref. 2012, 6, 135-145. [CrossRef]

31. Susmozas, A.; Moreno, A.D.; Romero-García, J.M.; Manzanares, P.; Ballesteros, M. Designing an olive tree pruning biorefinery for the production of bioethanol, xylitol and antioxidants: A techno-economic assessment. Holzforschung 2019, 73, 15-23. [CrossRef]

32. Gutiérrez, M.C.; Rosas, J.M.; Rodríguez-Cano, M.A.; López-Luque, I.; Rodríguez-Mirasol, J.; Cordero, T. Strategic situation, design and simulation of a biorefinery in Andalusia. Energy Conv. Manag. 2019, 182, 201-214. [CrossRef]

33. Romero-García, J.M.; Sanchez, A.; Rendón-Acosta, G.; Martínez-Patiño, J.C.; Ruiz, E.; Magaña, G.; Castro, E. An olive tree pruning biorefinery for co-producing high value-added bioproducts and biofuels: Economic and energy efficiency analysis. Bioenerg. Res. 2016, 9, 1070-1086. [CrossRef]

34. Martínez-Patiño, J.C.; Ruiz, E.; Cara, C.; Romero, I.; Castro, E. Advanced bioethanol production from olive tree biomass using different bioconversion schemes. Biochem. Eng. J. 2018, 137, 172-181. [CrossRef]

35. Gómez-Cruz, I.; Cara, C.; Romero, I.; Castro, E.; Gullón, B. Valorization of exhausted olive pomace by an eco-friendly extraction process of natural antioxidants. Antioxidants 2020, 9, 1010. [CrossRef] [PubMed]

36. Gómez-Cruz, I.; Contreras, M.D.M.; Romero, I.; Castro, E. A biorefinery approach to obtain antioxidants, lignin and sugars from exhausted olive pomace. J. Ind. Eng. Chem. 2021, 96, 356-363. [CrossRef]

37. Manzanares, P.; Ballesteros, I.; Negro, M.J.; González, A.; Oliva, J.M.; Ballesteros, M. Processing of extracted olive oil pomace residue by hydrothermal or dilute acid pretreatment and enzymatic hydrolysis in a biorefinery context. Renew. Energy 2020, 145, 1235-1245. [CrossRef]

38. Padilla-Rascón, C.; Ruiz, E.; Romero, I.; Castro, E.; Oliva, J.M.; Ballesteros, I.; Manzanares, P. Valorisation of olive stone by-product for sugar production using a sequential acid/steam explosion pretreatment. Ind. Crop. Prod. 2020, 148, 112279. [CrossRef]

39. Lama-Muñoz, A.; Contreras, M.D.M.; Espínola, F.; Moya, M.; Romero, I.; Castro, E. Optimization of oleuropein and luteolin-7-oglucoside extraction from olive leaves by ultrasound-assisted technology. Energies 2019, 12, 2486. [CrossRef]

40. Lama-Muñoz, A.; Contreras, M.D.M.; Espínola, F.; Moya, M.; Romero, I.; Castro, E. Content of phenolic compounds and mannitol in olive leaves extracts from six Spanish cultivars: Extraction with the Soxhlet method and pressurized liquids. Food Chem. 2020, 320, 126626. [CrossRef] [PubMed]

41. Contreras, M.D.M.; Lama-Muñoz, A.; Gutiérrez-Pérez, J.M.; Espínola, F.; Moya, M.; Romero, I.; Castro, E. Integrated process for sequential extraction of bioactive phenolic compounds and proteins from mill and field olive leaves and effects on the lignocellulosic profile. Foods 2019, 8, 531. [CrossRef] [PubMed] 